\title{
THE SOLIDIFICATION EFFECTS OF ADMIXING ACTIVATED STEEL SLAG WITH DREDGED MARINE SILTS
}

\author{
Chee-Ming Chan
}

\begin{abstract}
Regular dredging works are necessary for the development of coastal regions and the maintenance of shipping channels. However indiscriminate disposal of the dredged soils in open waters can cause severe and irreversible impact on the marine ecosystem. It is therefore desirable to transform the otherwise waste material into reusable soils, though some form of pre-treatment is necessary to improve the material's strength and stiffness. This paper describes an exploratory work of admixing dredged marine sediments of predominantly silt contents with activated steel slag for improvement of the mechanical properties. By first identifying the optimum activation concentration of $\mathrm{NaOH}$ for the steel slag, the solution was next introduced to the soil-slag mixture for uniform blending. Specimens were prepared per dry weight at ratios of clay : steel slag $=3: 7,5: 5$ and $7: 3$, then left to cure for up to 4 weeks. At intervals of 3, 7, 14 and 28 days, bender element and unconfined compressive strength tests were conducted to determine the changes in strength (unconfined compressive strength, $q_{u}$ ) and stiffness (based on $P$-wave velocity, $\left.v_{p}\right)$. Generally it was found that both $q_{u}$ and $v_{p}$ increased with higher steel slag content and longer curing time, though the increment rate was dependent on the soil type. The solidified specimens also showed improved ductility with greater failure strains. In conclusion, steel slag addition to the dredged sediments could effectively strengthen and stiffen the originally weak soil structure by (1) 'cementation' effect of the finer slag particles and (2) 'filler' effect of the coarser slag particles. The combined effects were however not distinguished in the present study.
\end{abstract}

Keywords - dredged soils, solidification, steel slag, strength, stiffness, bender element

\section{Introduction}

Dredging is the operation of removing material from one part of the water environment and relocating it to another. Dredging is carried out in many different locations and for many different purposes, but the main objectives are usually to recover materials which have some values to use, or to create greater depths of water. The developing works in coastal areas involve dredging for construction of structures, such as ports, waterways and breakwaters, land reclamation, and widen sections of the river or sea to facilitate economic activities, or to erect coastal protection systems.

Chee-Ming Chan

Faculty of Engineering Technology, Universiti Tun Hussein Onn Malaysia 864000, Batu Pahat, Johor, Malaysia

chan@uthm.edu.my or cheeming76@live.com
Perhaps the less well known but equally important purpose of dredging is the maintenance of port facilities. Dredging works at sea may be defined as the transfer process and removal of soil at the bottom of the sea to increase the sea depth, with the main purpose of keeping harbours and waterways accessible [1]. Dredging could be performed at ponds and lakes, rivers and rivemouth, port and harbours, bays and inlets. For example, during the large scale construction of Busan New Mega Port in Korea, a large amount of sediments has been dredged from the seabased construction site in order to remove siltation in the navigation channel and to restore a viable marine environment [2].

Technically, dredging involves relocation of underwater sediments and soils for offshore construction, maintenance of waterways, reclamation and soil improvement. The process produces a very large amount of dredged materials. It was reported that between tens of millions of tonnes of materials were dredged from the English and Welsh ports, harbours and their approach channels every year, where in 1994 alone the amount of dredged material was estimated at some 40 million tonnes [3]. Dredged soils are considered as a waste. Commonly, they are dumped into open sea, or disposed of in special landfills. Although the normal dredged material is not heavily contaminated, some can be subjected to high-risk contaminants. There is a variety of harmful substances, including heavy metals, oil, tributyltin (TBT), polychlorinated biphenyls (PCBs) and pesticides, which can be easily found on the seabed sediments in ports and harbours. The dredging and disposal processes can release these contaminants into the water column, making them available to be taken up by animals or plants and propagation, with the potential to cause contamination and poisoning over a larger area. Contaminated dredged soils are harmful and could degrade the marine environment and result in long term, irreversible damages. Whether in the extraction operation or in the relocation stage, precautionary actions must be taken to minimize disturbance to the marine life.

On a separate note, steel slag is a steel-making waste that could remain in the environment for hundreds of years because it cannot be decomposed to anything else at temperatures that exist in nature [4]. According to [5], steel slag is a by-product from either the conversion of iron to steel in a basic oxygen furnace (BOF) or the melting of scrap to make steel in an electric arc furnace (EAF). According to Kourounis et al. [6], 50 million tons of steel slag was produced worldwide every year, where Europe alone produced 12 million tons of steel slag per year. For the last 30 years though, intensive research work has helped to assign about $65 \%$ of steel slag for reuse y in qualified fields 
of applications. However the remaining $35 \%$ of steel slag were still dumped as a waste material.

Due to the slag's hardness and likeness to naturally sourced aggregates, steel slag has found its way into reuse in many engineering works, though some remain unusable for contamination issues [7]. In Germany and most other industrialised countries, blast furnace and steel slags are used as an aggregate for civil engineering works [8]. Steel slag is also known for its solidification properties, such as reported by [9] and [10]. Nonetheless most metallurgical slags are used as aggregates for different applications, and only the ground granulated blast furnace slag is used for a partial Portland cement replacement [6]. The inherent cementitious and/or pozzolanic properties of steel slag make it a potential alternative binder for soil solidification. This is a desirable feature for additives to solidify poor quality soils with low bearing capacity and high compressibility, such as dredged marine soils. If the materials could be mixed and transformed into a uniform mixture, the steel slag's cementitious property could effectively bind the soil particles into a stronger and stiffer form for reuse as a good soil. As reported by Lindmark et al. [11], the slag-treated soils can be used as filling material in ports as replacement for conventional filling material. Kamali et al. [12] also found the treated material to be usable in road engineering as sub-base and base course materials.

The present study attempts to determine the potential of steel slag in solidifying dredged marine silts. 2 soil samples were collected from local dredging sites for the project, with steel slag sourced from a local steel-making plant. The slag was first activated with $\mathrm{NaOH}$ to enhance the solidification potency. It was hypothesized that if the slag could effectively improve the strength of the dredged soil, it could be reused as a sound engineering soil with reasonably good engineering properties. This could help reduce dumping of the material offshore, and avoid the negative impact associated with the disposal method, not to mention the added benefits of creating a sustainable solution to the otherwise discarded materials. Different mix ratios were examined and the test specimens were allowed to mature for up to a month. The relevant laboratory tests were performed to measure the improved engineering properties, i.e. strength and stiffness, at predetermined curing periods.

\section{Materials and Methods}

\section{A. Dredged Marine Soils}

The samples used in the present study were bulk samples collected immediately upon removal from the seabed. As a backhoe dredger was used for the dredging works, samples were manually scooped from the backhoe and stored in sampling bags for transportation to the laboratory (Figure 1). The dredged marine soil was in a slurry form, dark grey in colour and contained some shell fragments and other debris commonly found in nearshore deposits. Figure 2 shows the shell fragments extracted from the soil. Relatively large and visually discernible with naked eyes, the fragments were manually removed from the soil sample prior to mixing in laboratory. Such large pieces of debris would have been detrimental to the uniformity of mixing with the steel slag if left in the soil, leading to segregation and non-uniform distribution of the cementation matrix. Considering that the soil samples were disturbed but representative of the field conditions, they were remoulded by manual and mechanical mixing prior to use in the test series. Note that in order to control the mixing water content when admixed with steel slag, the dredged soil was initially oven-dried for 24 hours, then crushed and ground to its original fine particles $(<425$ $\mu \mathrm{m})$ for the solidification study. This enabled a careful control of the mix ratios of each constituents in the mixture, i.e. soil, slag and water contents. The mixing water content for the soil-slag mixture was fixed at 0.75 times the liquid limit. Table 1 summarizes the physical properties of both the dredged marine soil samples.

\section{TABLE I. PROPERTIES OF DREDGED MARINE SAMPLES}

\begin{tabular}{l|c|c}
\hline \multicolumn{1}{c|}{ Properties } & Sample A & Sample B \\
\hline${\text { Natural water content, } \mathrm{W}_{\mathrm{nat}}}_{\text {Specific gravity, } \mathrm{G}_{\mathrm{s}}}$ & $130.7 \%$ & $118.5 \%$ \\
Liquid limit, LL & 2.53 & 2.95 \\
Plastic limit, PL & $66 \%$ & $36.3 \%$ \\
Soil type & $56.1 \%$. & $32.6 \%$ \\
& $\mathrm{MH}$ & $\mathrm{ML}$ \\
& (high plasticity silt) & (low plasticity silt) \\
\hline
\end{tabular}

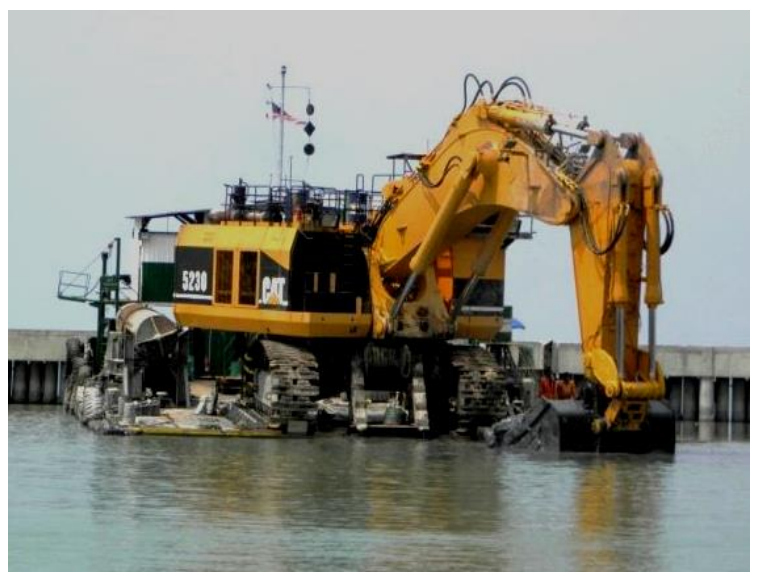

Figure 1. Backhoe dredger.

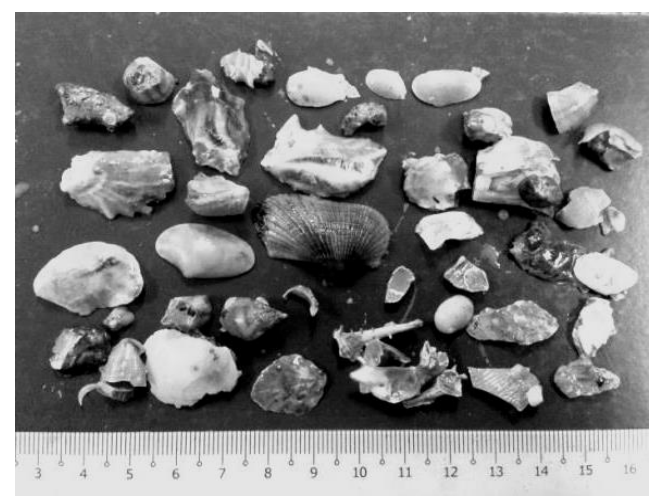

Figure 2. Shell fragments extracted from the dredged soil

\section{B. Steel Slag}

An arc electric furnace (EAF) steel slag was used in the present study. As received, the steel slag were in chunks of 20-60 mm, clearly unsuitable for mixing with the soil and producing test specimens of relatively small dimensions, i.e. $38 \mathrm{~mm}$ diameter and $76 \mathrm{~mm}$ height. It was therefore crushed 
and ground with an industrial grinder into finer particles, where only those passing the $2 \mathrm{~mm}$ sieve were used in the specimen preparation. The ground slag was stored in airtight containers at room temperature of $20^{\circ} \mathrm{C}$ to avoid oxidation of the ground slag when exposed to moisture in the air.

The grinding process has a significant implication on the subsequent mixing and solidifying processes. Firstly, the steel slag was physically reduced to smaller fractions for ease of mixing with the soil. Secondly, the size reduction process actually helped increase the exposed surface of the steel slag for reaction in the soil mass. Thirdly, and perhaps most importantly, the finer slag particles with the 'nonreacted' inner surfaces enabled greater chemical reaction and hence solidification of the wet soil.

\section{Alkaline-Activation Steel Slag}

According to Shi [5], the cementing properties of activated steel slag using alkaline is higher than raw steel slag due to the chemical reactions between the steel slag and sodium hydroxide $(\mathrm{NaOH})$, with enhanced cementitious properties with room temperature curing and presence of finer slag particles. The most commonly used alkaline activators are sodium hydroxide, potassium hydroxide, sodium waterglass and potassium waterglass [13]. All these activators have some common properties: caustic, corrosive and highly hazardous. Among these chemicals, $\mathrm{NaOH}$ arguable finds the widest use in industrial applications due to both its low price and availability in various forms, i.e. granules, flakes, or pellets. A $\mathrm{NaOH}$ : steel slag ratio of 30 $\%$, based on steel slag in dry condition and the $\mathrm{NaOH}$ in liquid form for mixing was recommended by Wang and Yan [7].

Based on the recommendations above, $\mathrm{NaOH}$ was used as the steel slag activator in the present study. In order to determine the most suitable molarity of $\mathrm{NaOH}$ for solidifying the dredged soil, trial strength tests with a range of molarity was carried out. The $\mathrm{NaOH}$ dilution was prepared by mixing $\mathrm{NaOH}$ pallets with distilled water to form solutions of 2, 4, 6, 8 and 10 mols. A mixture of soil and steel slag at the ratio of 1:1 was added to the solutions respectively. Irrespective of the soil sample used (i.e. sample A or B), a generally declining trend was observed between the strength and molarity of the $\mathrm{NaOH}$ solution from 4 mol onwards. Hence $4 \mathrm{~mol}$ of $\mathrm{NaOH}$ was used throughout the study for preparing the soil-slag mixtures.

As $\mathrm{NaOH}$ was introduced to the soil-slag mixture in liquid form, the amount added was taken to be the mixing water content too, which was prefixed $0.75 \mathrm{LL}$ of the soil. This was essential to ensure ease of achieving uniformity in mixing, yet not producing a mixture which was too wet to be formed into cylindrical specimens for storage and subsequent tests. Note too that the highly hydroscopic nature of $\mathrm{NaOH}$ could potentially have contributed to drying of the soil-slag mixture, leading to better strength and stiffness gains.

\section{Preparation of Specimens}

The soil : slag ratio (dry weight) was varied between $3: 7$, $5: 5$ and $7: 3$, to examine the effect of various dosages of slag addition to the soil. The dry soil and steel slag were first manually mixed in the mixing bowl of a conventional kitchen mixer before the addition of the $4 \mathrm{~mol} \mathrm{NaOH}$ solution at an equivalent $0.75 \mathrm{LL}$ mixing water content. The mechanical mixing was maintained for 10 minutes to ensure even mixing of the materials. The homogeneous mixture was then transferred into a cylindrical steel mould $(38 \mathrm{~mm}$ diameter, $76 \mathrm{~mm}$ height) and the mould was tapped to remove any entrapped air. 70 times of tapping was adopted for each layer of mixture placed in the mould, where 4 sequential placement and tapping of the layers were found to produce a satisfactorily compacted, homogenised specimen. Extruded from the mould, the specimens were carefully wrapped and sealed tightly using plastic food wrapper to prevent loss of moisture due to evaporation. The specimens were left to cure up to a month in a storage box with raised platforms, with tests being carried out on day 3, 7, 14 and 28. A bleach and water solution was introduced beneath the raised platform to prevent fungal growth on the specimens during the extended curing period. A pair of specimens for each mix ratio and curing period was prepared. Considering that the bender element test is non-destructive, it was first conducted on the specimens before the unconfined compressive strength (UCS) test, which loaded the specimen to failure and destruction.

\section{Test and Measurements}

\section{A. Bender Element (BE) Test}

The P-velocity $\left(v_{p}\right)$ is determined by using the bender element (BE) test setup by GDS UK, as shown in Figure 3. The piezoelectric properties of the bender elements enable it to convert an electrical energy into kinetic form and vice versa. As such, the transmitter BE is first activated with a voltage to initiate vibration of the bender element. The vibration is then transferred to the soil medium and P-waves propagate through the specimen. On the opposite end, the initially at-rest receiver bender element picks up the vibration sent through the specimen and begins to vibrate itself. The vibration of the receiver, albeit small, generates a small voltage, which can be captured as a waveform on an oscilloscope or its manifestation via a computer programme on screen. A sinusoidal waveform, $10 \mathrm{kHz}$ frequency, $\pm 10 \mathrm{~V}$ amplitude, was used to trigger the transmitter bender element to generate $\mathrm{P}$-waves. The readings per channel were taken at 100,000 samples per second within $10 \mathrm{~ms}$ of sampling time. An example of the transmitted and received $\mathrm{P}$-wave is shown in Figure 4.

With the $v_{p}$, the small strain bulk modulus $(K)$ can be determined. This follows that $\mathrm{v}_{\mathrm{p}}$ is determined by simply taking the tip-to-tip travel distance between the transmitter and receiver bender elements (L) divided by the travel time (t). Assuming that the soil medium is homogeneous, isotropic and elastic, a multiplication of the bulk density of the medium's material $(\rho)$ and the square of $v_{p}$ would give the bulk modulus $(\mathrm{K})$, i.e. $\mathrm{K}=\rho \mathrm{v}_{\mathrm{p}}{ }^{2}=\rho(\mathrm{L} / \mathrm{t})^{2}$. The determination of the travel time $(\mathrm{t})$ is shown in Figure 4 too, i.e. the peak-to-peak method, where $t$ is taken to be the lapse between the first peaks of the transmitted and received signals. 


\section{B. Unconfined Compressive Strength (UCS) Test}

A standard equipment was used for the unconfined compressive strength test. The unconfined compression strength $\left(\mathrm{q}_{\mathrm{u}}\right)$ is defined as the maximum unit axial compressive stress at failure. The test was conducted in accordance with the procedure given in [14], with vertical load being applied to produce axial strain at a rate of $2 \%$ per minute. Simple as the test may be, a number of sources of error could arise [15], i.e. (i) the use of unrepresentative specimen, (ii) end effects caused by the gripping top and bottom loading plates, and (iii) buckling of an overlong specimen. In the present study, care was taken in the mixing and moulding processes to ensure uniform specimens were produced. The specimen ends were also trimmed flat and kept moist to prevent end effects. The height to diameter ratio of the specimen was no more than 3 to avoid buckling issues. Note too that random samples were taken from the stored bulk samples retrieved from site and subjected to the vane shear test. At natural water contents which exceeded the LL, both soil samples registered undrained shear strength of $<15 \mathrm{kPa}$ on the scale of the apparatus.

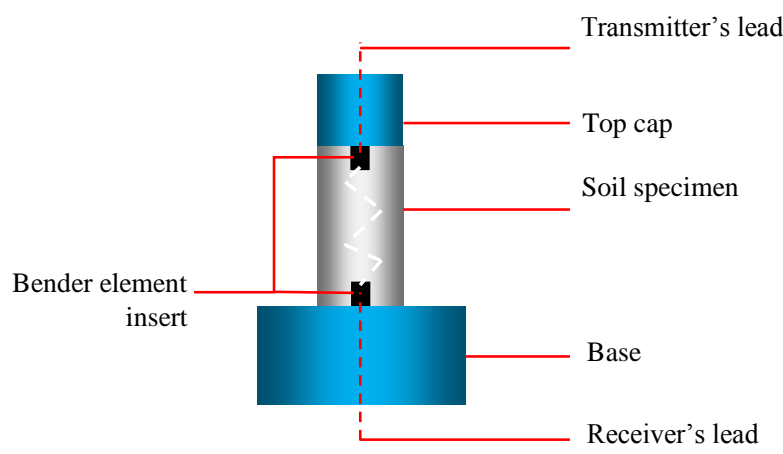

Figure 3. Bender element test setup.

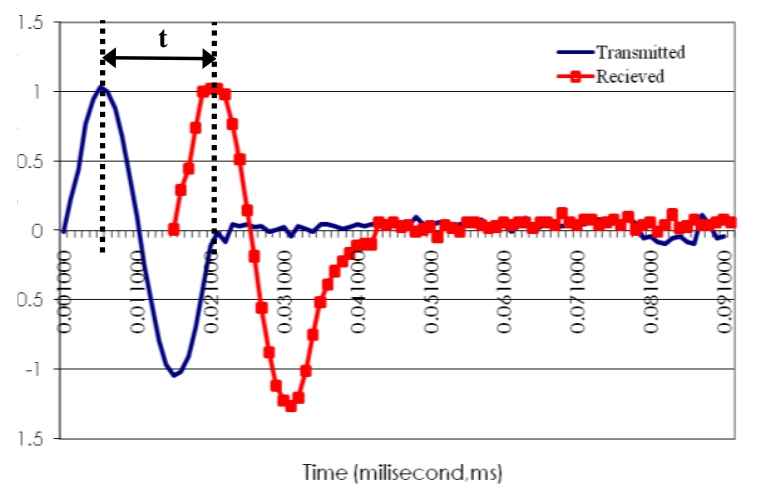

Figure 4. Transmitted and received P-waves from BE test (normalised amplitude).

\section{Iv. Results, Analysis and Discussions}

\section{A. Curing Period Effect}

Figures 5-8 summarize the normalised results for the specimens in plots against the curing period. Note that the normalisation referred to the 3-day measurement as the denominator. Looking at Figure 5, generally speaking, $\mathrm{v}_{\mathrm{p}}$ increased with longer time lapse, though Sample B clearly underwent more significant stiffness gain during the 28-day curing period. Ignoring the final spike of $\mathrm{v}_{\mathrm{p}}$ for specimen $7: 3$ of Sample A, the trend for Sample A indicates marked improvement up to only first week of curing, after which the stiffness remained largely unchanged. As for Sample B, there appeared to be a continuous rise in $\mathrm{v}_{\mathrm{p}}$ beyond 28 days despite the same slag addition ratio as Sample A (not covered in the present study). Also, the $v_{p}$ increment ratio was more encouraging than that of Sample A, i.e. 2.5 times increment for Sample B compared to 1.5 times for Sample A. It could therefore be said that Sample B was more effectively solidified based on the bender element measurements.

The strength gain pattern shown in Figure 6 gives a different perspective to the solidification efficacy of the $\mathrm{NaOH}$-activated steel slag in the dredged marine soil samples. With a much gentler rise for the first 2 weeks, Sample A demonstrated a sudden increment in $\mathrm{q}_{\mathrm{u}}$ within the last 2 weeks of curing. In comparison, Sample B's $q_{u}$ increment was more uniform, with an average double increment in $\mathrm{q}_{\mathrm{u}}$ over the 28-day period. As such, both samples reached the same $\mathrm{q}_{\mathrm{u}}$ increment ratio over 4 weeks (i.e. double the $\mathrm{q}_{\mathrm{u}}$ at 3 days), but at a different rate. This is important in field implementation when the design or desired strength needs to be attained within a certain stipulated time. For instance, in a fortnight's time, at the same soil : slag mixtures, the improvement ratio of Sample A would be lower than that of Sample B. If greater strength gain is required within a shorter period, Sample B would be the preferable choice of backfill material. However, if time factor is not critical, either soil sample is acceptable as they attain the same strength gain ratio by 28 day. Of course, this is notwithstanding the actual strength of the respective samples when admixed with activated steel slag.

As mentioned in III(A), $\mathrm{v}_{\mathrm{p}}$ is an indirect indicator of the small strain stiffness, as represented by the bulk modulus $(\mathrm{K})$. The normalised $\mathrm{K}$ values are shown in Figure 7. The increment pattern of $\mathrm{K}$ is in line with those observed in $\mathrm{v}_{\mathrm{p}}$ (Figure 5). The rise in $\mathrm{K} / \mathrm{K}_{3}$ was as high as 7 for Sample $\mathrm{B}$ but was less remarkable in Sample A with an average of 4. The almost $100 \%$ difference between the small strain stiffness gain rate of the 2 samples again pointed to the more reactive nature of the soil-slag mix of Sample B. This is notwithstanding the sharp ascent from 14 to 28 days for Specimen 7:3 of Sample A and the plateau seen in the plot for Specimen 5:5 of Sample B in Figure 7, which could be due to experimental errors not uncommon in the relatively sensitive bender element tests.

Interestingly, the normalised Young's modulus plot in Figure 8 showed an obviously more subdued rise over the 28-day curing period. In fact, the increment was barely over twice the initial stiffness in both samples. In comparison to the small strain stiffness gain $(\mathrm{K})$, the far lower increment, especially for Sample B, suggests that the actual stiffness could be masked by the various errors associated with unconfined compressive strength test highlighted in III(B). Nonetheless the $\mathrm{q}_{\mathrm{u}}$ and $\mathrm{E}$ plots are consistent with one another, with the 28-day curing period resulting in approximately $100 \%$ increment in the large strain strength and stiffness, i.e. $\mathrm{q}_{\mathrm{u}} / \mathrm{q}_{\mathrm{u} 3} \approx \mathrm{E} / \mathrm{E}_{3} \approx 2$. The seeming discrepancies could be explained by the possible nonuniformity of the slag particle distribution in the soil-slag specimens, resulting in localised weak zones where 
Proc. of The Fifth Intl. Conf. On Advances in Civil and Structural Engineering - CSE 2016

Copyright $($ Institute of Research Engineers and Doctors, USA .All rights reserved.

ISBN: 978-1-63248-088-0 doi: 10.15224/ 978-1-63248-088-0-68
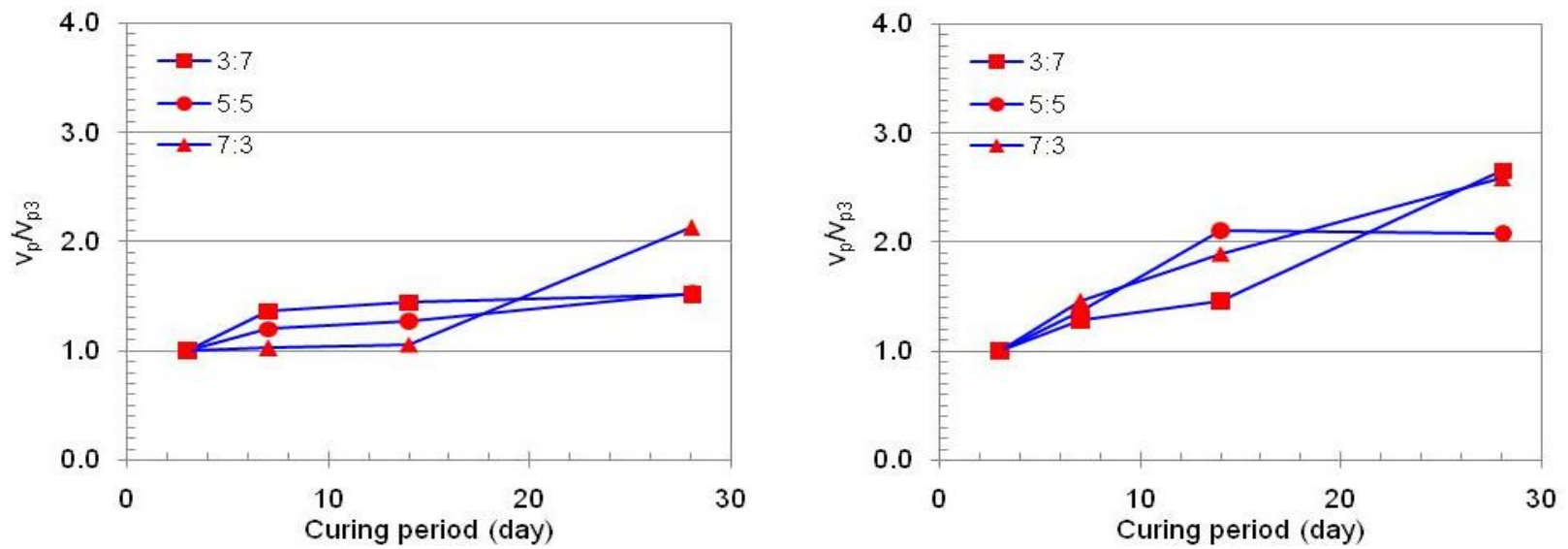

Figure 5. Normalised $v_{p}$ over the curing period.
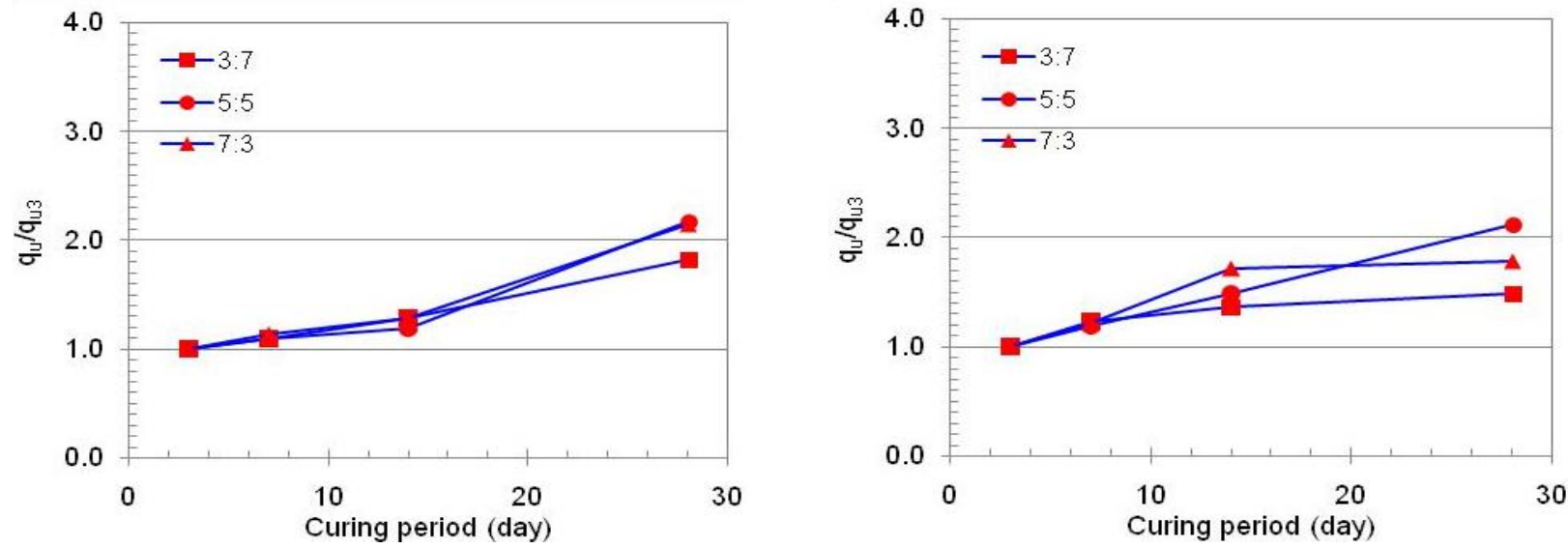

Figure 6. Normalised $\mathrm{q}_{\mathrm{u}}$ over the curing period.
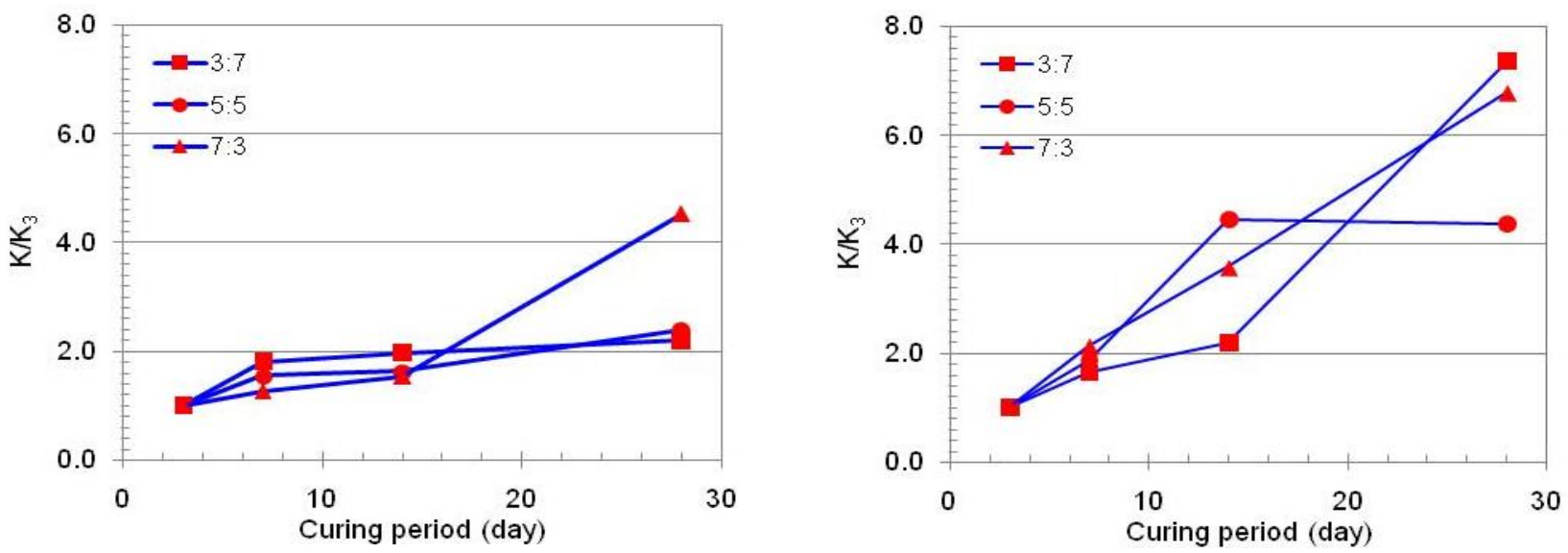

Figure 7 Normalised K versus the curing period.
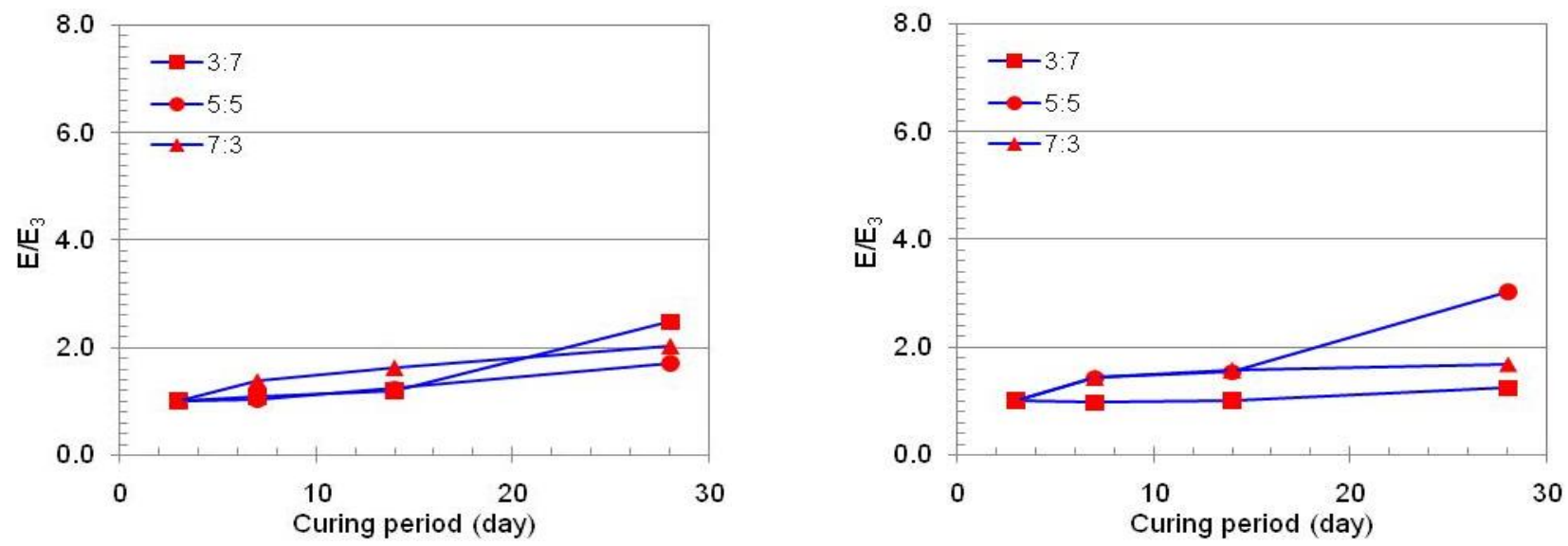

Figure 8. Normalised E versus the curing period. 
Proc. of The Fifth Intl. Conf. On Advances in Civil and Structural Engineering - CSE 2016

Copyright $($ Institute of Research Engineers and Doctors, USA .All rights reserved.

ISBN: 978-1-63248-088-0 doi: 10.15224/ 978-1-63248-088-0-68

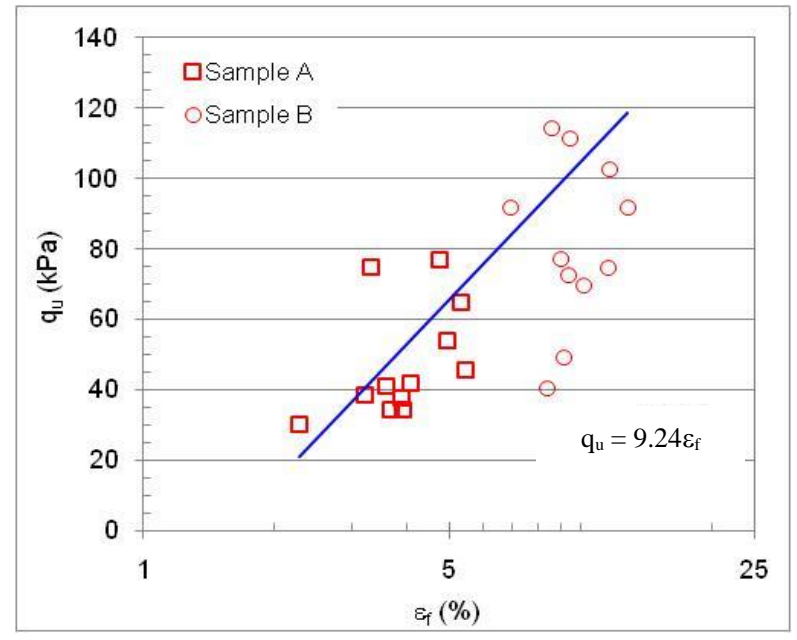

Figure 9. $\mathrm{q}_{\mathrm{u}}-\varepsilon_{\mathrm{f}}$.

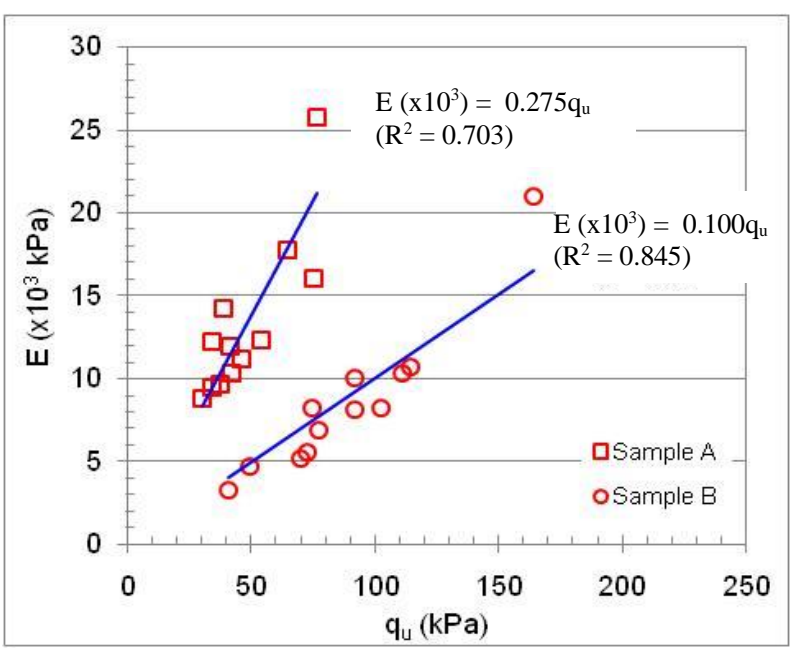

Figure 10. E - $q_{u}$.

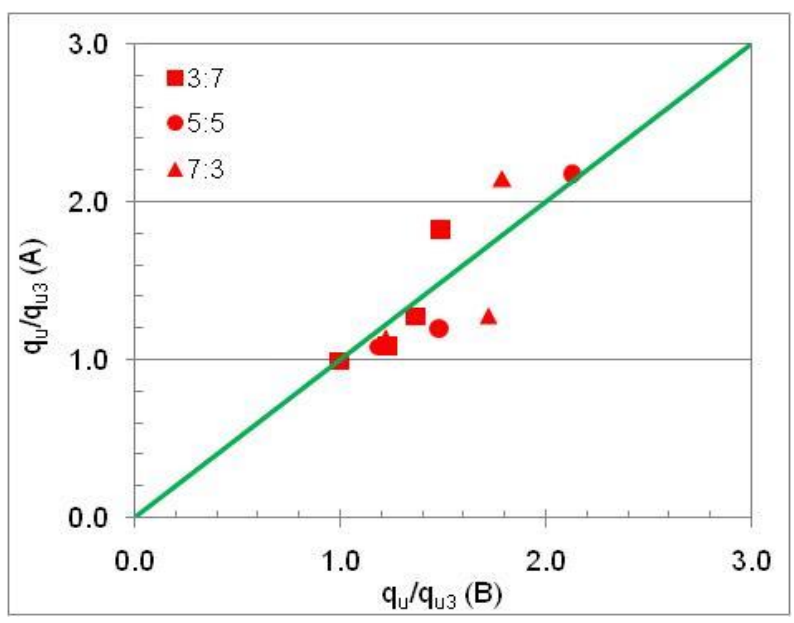

Figure 11. $\mathrm{q}_{\mathrm{u}} / \mathrm{q}_{\mathrm{u} 3}$ for Samples A and B.

solidification was less satisfactory than the other zones with higher concentration of slag. Besides, the percentage of nonreactive slag available in a particular zone could affect the overall stiffness distribution. Considering that EAF slag is a by-product of steel-making as derived from the high temperature processes on the feeder scrap metal, it is understandable if the material's properties are inconsistent with high variability even within the same production batch.

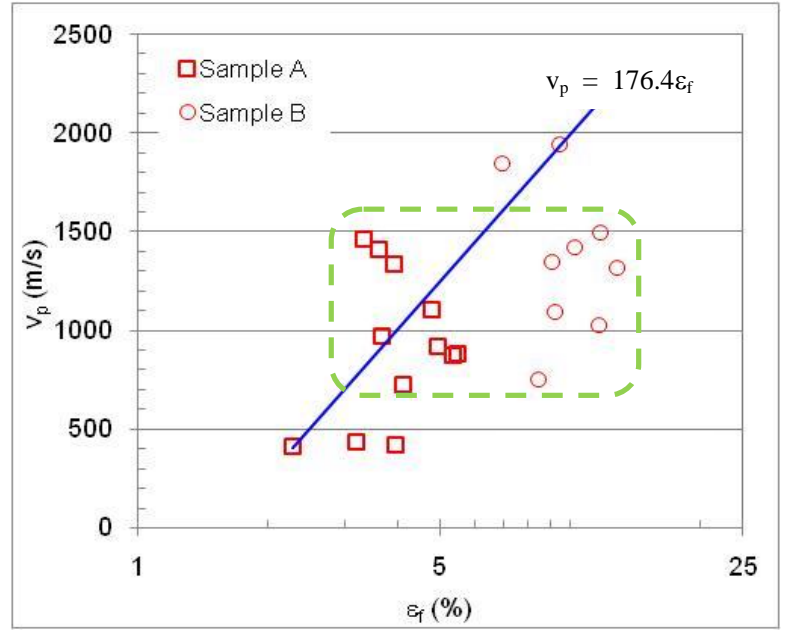

Figure 12. $v_{\mathrm{p}}-\square_{\mathrm{f}}$.

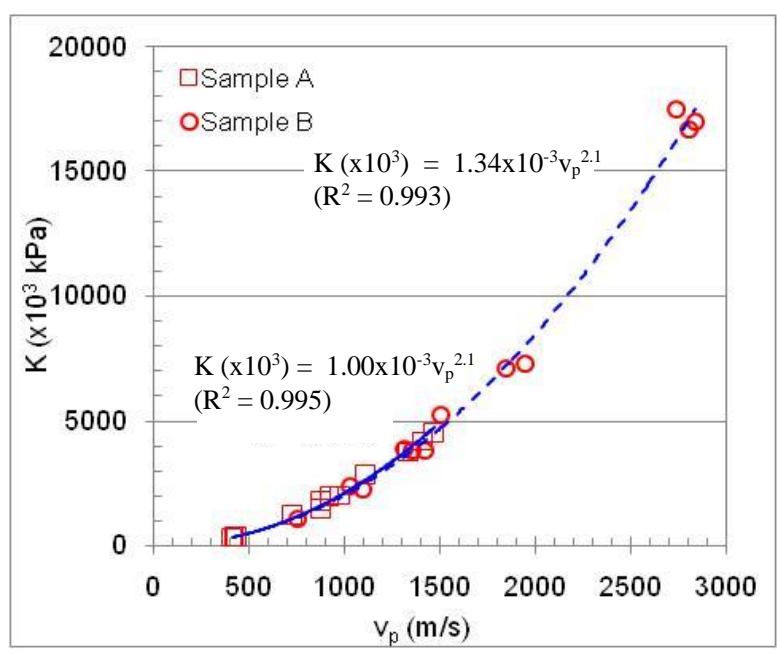

Figure 13. $\mathrm{K}-\mathrm{v}_{\mathrm{p}}$.

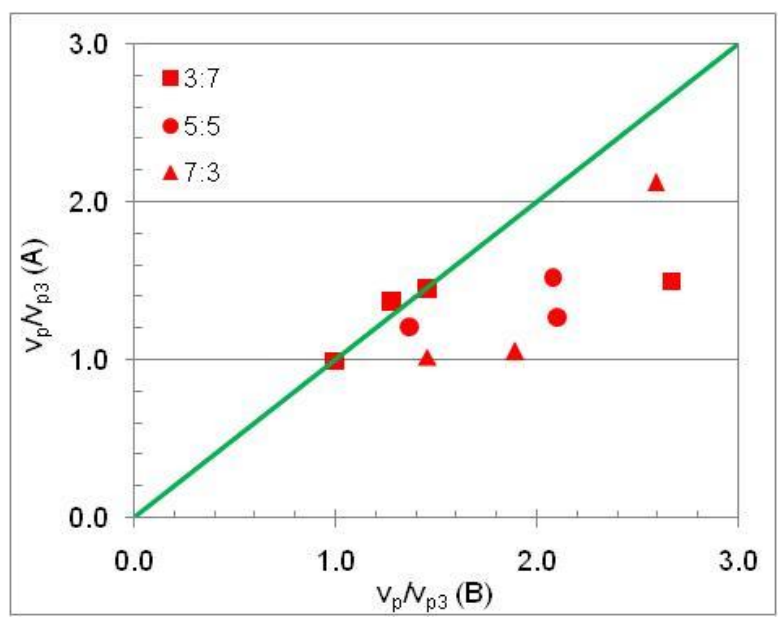

Figure 14. $\mathrm{v}_{\mathrm{p}} / \mathrm{v}_{\mathrm{p} 3}$ for Samples A and B.

The individual trend lines for $\mathrm{v}_{\mathrm{p}}, \mathrm{q}_{\mathrm{u}}$ and the corresponding $\mathrm{K}$ and $\mathrm{E}$ in Figures $5-8$ also revealed that higher dosages of slag do not necessarily produce greater solidification effects. Indeed Sample A showed marginal difference in the solidification effect within the range of soil : slag ratio examined, as demonstrated by the overlapping data points in the figures. Despite showing more significant strength and stiffness gain with time, Sample B displayed conflicting results between large and small strain range. 


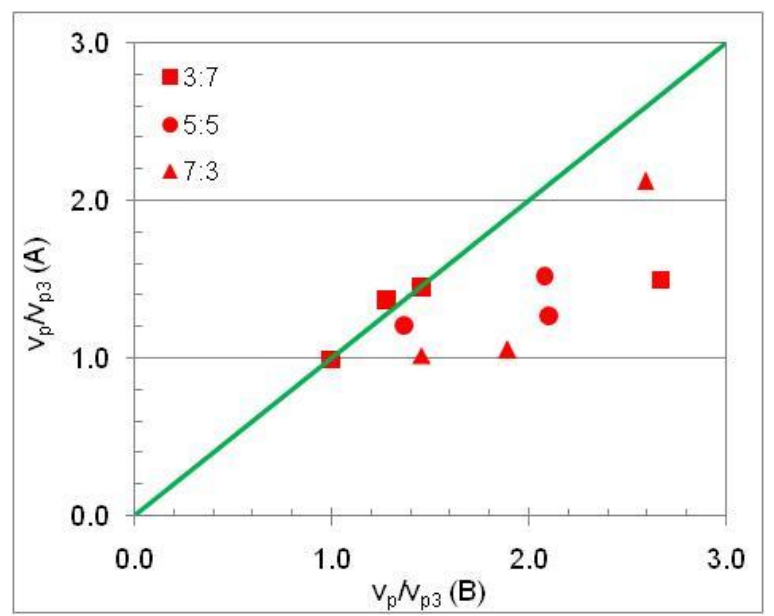

Figure 14. $\mathrm{v}_{\mathrm{p}} / \mathrm{v}_{\mathrm{p} 3}$ for Samples A and B.

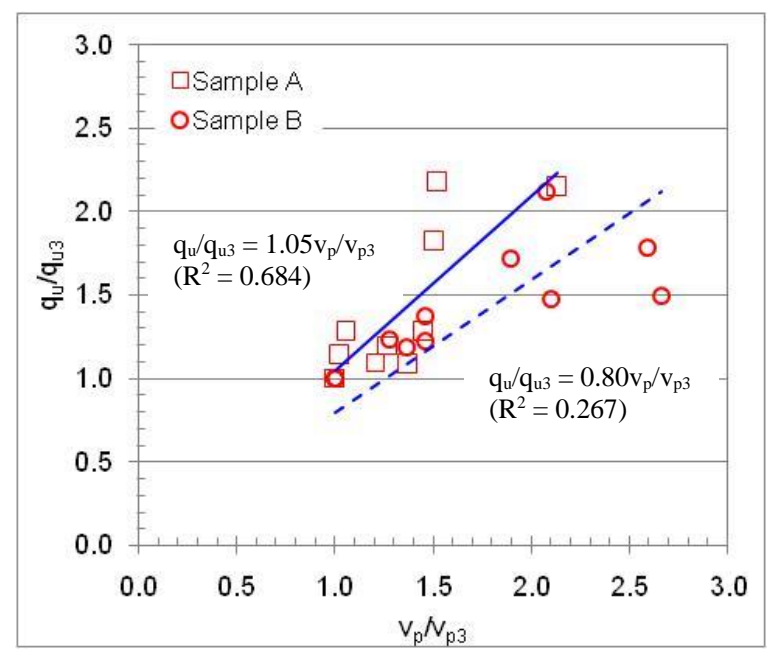

Figure 15. Normalised $\mathrm{q}_{\mathrm{u}}-\mathrm{v}_{\mathrm{p}}$ plots.

Taking into account the cementitious properties of slag, the $\mathrm{v}_{\mathrm{p}}$ and $\mathrm{K}$ plots indicate enhanced stiffness with higher slag addition. The large strain test results, i.e. unconfined compressive strength test, on the other hand, suggests that the 5:5 mix ratio was optimal for strength and stiffness improvement. This seemingly contradicting observation sheds light on the probable crumbly nature of the soil-slag specimens due to excessive filler effect. While the bender element measurement was able to detect the stiffened microstructure due to solidification, the compression test revealed adverse effect of the excessive inclusion of the slag particles. As such, the cementation effect was overwhelmed by the crumbliness caused by the large amount of slag particles in the mixture. This is indicative of an optimum mix ratio for a given slag and soil mixture for maximum strength and stiffness improvement, probably heavily dependent on the slag's natural properties itself.

\section{B. Strength Measurement}

Figure 9 shows qu plotted against the failure strain, $\square$ f. Clearly the different soil types displayed respective yielding strength and strain ranges, with Sample B attaining higher strengths compared to Sample B. Nonetheless within overlapping $\mathrm{q}_{\mathrm{u}}$ region of $40-80 \mathrm{kPa}$ for both samples, the corresponding $\varepsilon_{\mathrm{f}}$ of Sample B $(\approx 5 \%)$ was almost double that of Sample A $(\approx 10 \%)$. The more significant deformation in Sample B prior to failure may be an indicator of failure by excessive subsidence instead of bearing capacity in practice. It is generally reported that for solidified soils, the yielding pattern under compressive load tends to be that of a sharp rise in stress followed by sudden failure at peak strength. This is however not observed in the soil-slag mixtures, where the solidified specimens with greater strength improvement demonstrated larger failure strains. This suggests that as the material stiffens, the inherent ability of the fine-grained soil to deform to a large extent before yielding was not totally obscured by the cementation effect of the steel slag. The rather flat yield approach followed by gradual failure was distinguishable in the stress-strain curves, evidence that certain amount of ductility was maintained within the soil despite slag addition.

The initial Young's modulus (E), as derived from the gradient of the first rise in the stress-strain curve is plotted with $\mathrm{q}_{\mathrm{u}}$ in Figure 10. Due to the different deformation pattern experienced by the solidified specimens under loading, Samples A and B demonstrated distinct E- $\mathrm{q}_{\mathrm{u}}$ relationships. While the linear correlation is not uncommon, both plots lying apart shows corroboration with the results in Figure 9. It can be seen that although Sample A had greater E values, Sample B attained higher $\mathrm{q}_{\mathrm{u}}$. Solidification with activated steel slag apparently did not result in the simultaneous enhancement of both parameters generally reported of similarly treated soils, where strength and stiffness are almost ubiquitously going hand in hand. On their own, both samples did show $\mathrm{q}_{\mathrm{u}}$ increasing with $\mathrm{E}$, but the amount of increment was clearly different.

The normalised strength data was derived simply by dividing the strength at any given age of the specimen with the strength at day 3 . The normalised $\mathrm{q}_{\mathrm{u}}$ was next plotted in Figure 11 for both samples. A 1:1 line is included in the figure for ease of reading. Note that regardless of the mix ratios, both samples showed fairly good distribution along the 1:1 reference line. As such, despite the differences in load-deformation responses discussed earlier, the strength improvement followed a similar trend for both samples.

\section{Stiffness Measurement}

Figure 12 shows the plot of $v_{p}$ versus $\varepsilon_{f}$. The plot is similar to the $\mathrm{q}_{\mathrm{u}}-\varepsilon_{\mathrm{f}}$ plot in Figure 9, i.e. clustering of the data according to soil sample, with the Sample B cluster lying above that of Sample A. It should however be cautioned that the strain involved in the $v_{p}$ measurements would have been very small $(<0.001 \%)$ compared to the large strains recorded in the compression test. This is merely a crosscheck exercise to relate the 2 measurements. It is noteworthy though that number of overlapping data points within the shared $\mathrm{v}_{\mathrm{p}}$ range, as corresponding with the same $\varepsilon_{\mathrm{f}}$ range in Figure 9, encompasses a larger number of data. It is suggestive of a mismatch between the small and large strain responses of the solidified soil, where the magnitude of failure deformation observed outwardly may not represent the material's response to loading at much lower strain levels.

The bulk modulus $(\mathrm{K})$ and the corresponding $\mathrm{v}_{\mathrm{p}}$ values are plotted against each other in Figure 13. Although separate trend lines were introduced for the respective samples, both data sets do appear to share a very similar relationship, i.e. approximately $1.17 \mathrm{v}_{\mathrm{p}}{ }^{2}$. Nonetheless Sample $\mathrm{B}$ does seem to register higher stiffness gain with the slag 
addition, with data points reaching well into the $15-20 \mathrm{MPa}$ range of $\mathrm{K}$. The quadratic correlation is also suggestive of the dramatic increment in stiffness with the more effectively solidified specimens, where a significant rise of the stiffness moduli observed from about $\mathrm{v}_{\mathrm{p}}=1500 \mathrm{~m} / \mathrm{s}$ onwards.

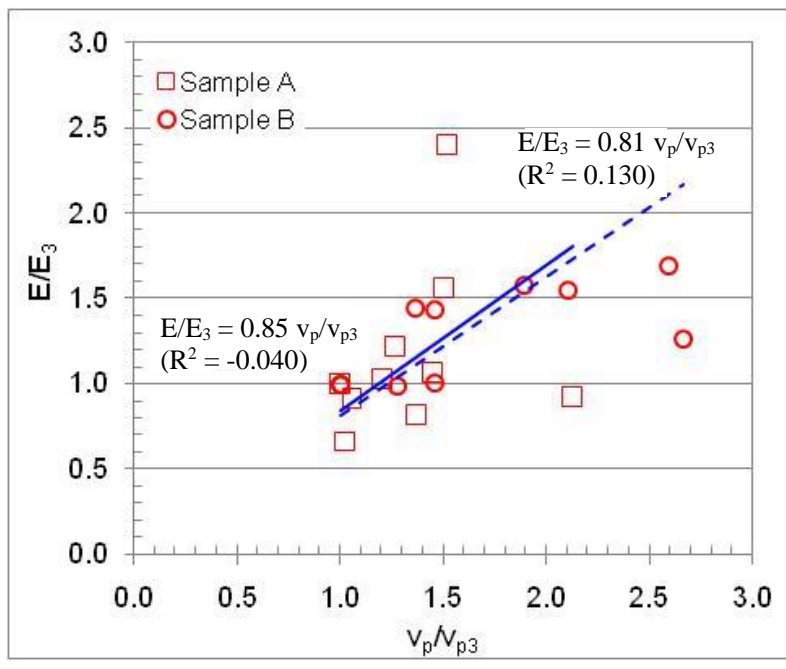

Figure 16. Normalised E - $v_{p}$ plots.

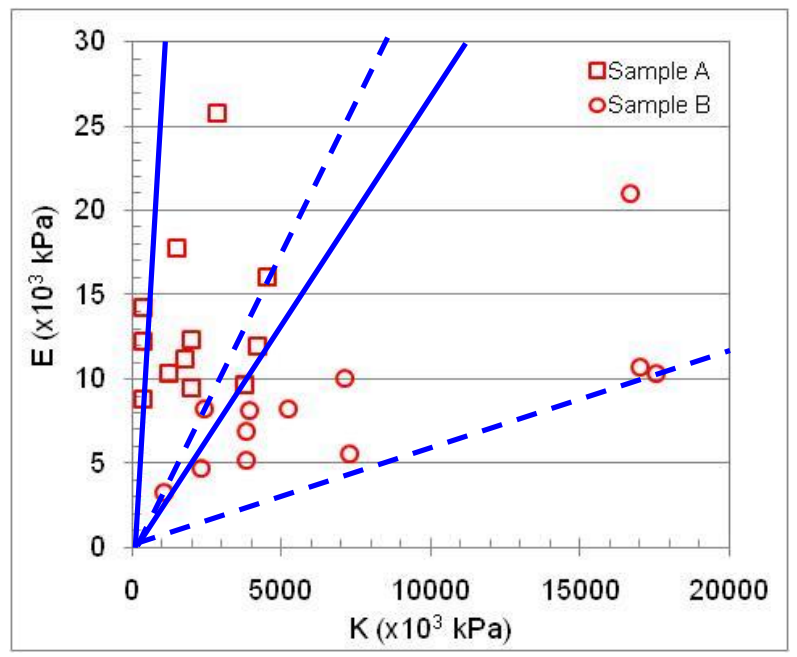

Figure 17. E-K.

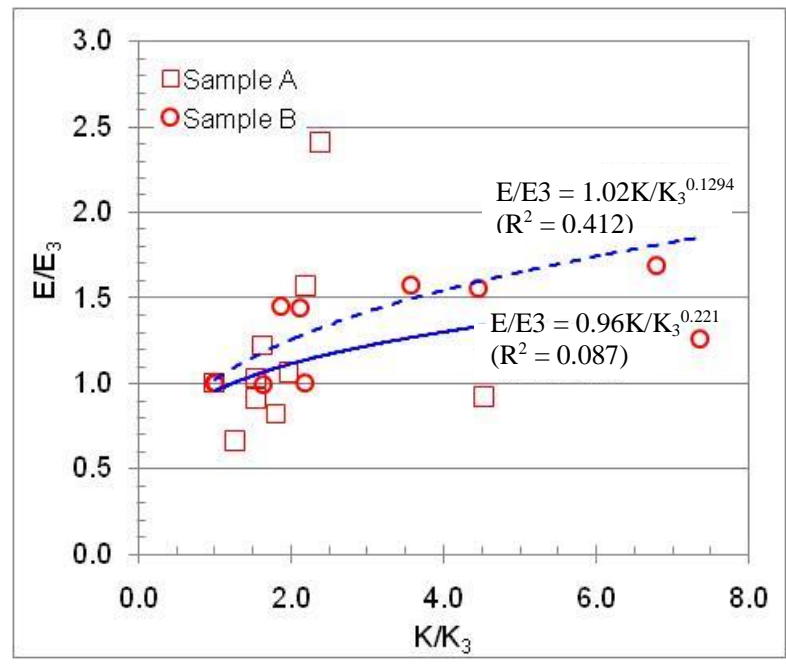

Figure $18 \mathrm{E} / \mathrm{E}_{3}-\mathrm{K} / \mathrm{K}_{3}$.
Similar to Figure 11, the normalised $\mathrm{v}_{\mathrm{p}}$ for both samples are plotted in Figure 14. The outlying scatter in the far right region indicates less marked increase in $v_{p}$ for Sample A. This is in accordance with the results discussed earlier showing greater stiffness gain in Sample B. It is however in contrast with the strength gain pattern in Figure 11, where both samples displayed similar improvement rate over the 28-day period.

\section{Strength-Stiffness Correlation}

The normalised $\mathrm{q}_{\mathrm{u}}$ and $\mathrm{v}_{\mathrm{p}}$ are plotted against each other in Figure 15. Linear correlations assigned to both samples show that Sample A underwent $20 \%$ more strength gain over the 1 month curing period compared to Sample B. Note that the difference is attributed to the individual strength gain pattern as elaborated earlier. It can also be seen from the plots in Figure 15 that the same percentage of slag addition produced comparable strength and stiffness improvements initially, with diversion taking place only in the higher $\mathrm{q}_{\mathrm{u}} / \mathrm{q}_{\mathrm{u} 3}$ and $\mathrm{v}_{\mathrm{p}} / \mathrm{v}_{\mathrm{p} 3}$ region. Hence depending on the target design strength or stiffness, both soils could be adequately solidified to serve for load-bearing with predictably similar results.

The normalised $E / E_{3}$ and $v_{p} / v_{p} 3$ plot in Figure 16 shows an almost overlapping linear trend lines for both samples. The scatter notwithstanding, the increment in the normalised $\mathrm{E}$ is approximately $83 \%$ of the $\mathrm{v}_{\mathrm{p}}$, indicating a more significant rise in the small strain stiffness gain. This is despite the fact that $\mathrm{E}$ was derived from the initial departure from origin of the stress-strain plot associated with the elastic region of deformation for the material.

Figure 17 shows the E-K plot, with the upper and lower boundaries for both samples included. It is apparent that both samples have their respective range of $\mathrm{E}$ and $\mathrm{K}$ values, though the small strain stiffness was clearly far larger than its counterpart derived from the large strain tests. Figure 18 shows the same data plotted in their normalised forms. The increment ratio for $\mathrm{K}$ is more significant compared to $\mathrm{E}$. Note that for Sample B, a significant rise in $K$ was not accompanied by a similar increment in $\mathrm{E}$, where the $\mathrm{K} / \mathrm{K}_{3}$ ranged over 1.0-7.5 while $\mathrm{E} / \mathrm{E}_{3}$ remained largely unchanged between 1.0-1.7. Besides, the clustering of the data of both samples in the region of $\mathrm{K} / \mathrm{K}_{3} 1.0-2.0$ points to the greater change in $\mathrm{K}$ compared to $\mathrm{E}$, suggesting possible underestimation of the stiffened structure of the solidified soils if relying on the derivation from stress-strain curve alone.

\section{v. Conclusions}

The $v_{p}$ increment was more significant in Sample B than Sample A over the 28-day curing period, suggesting more effective solidification in the low plasticity silt than its high plasticity counterpart. The $\mathrm{q}_{\mathrm{u}}$ increment ratio was uniform for Sample B throughout the 4 weeks but showed a sudden increment in Sample B over the final 2 weeks. The implication of this difference is especially obvious in field implementation of the materials in backfilled embankments. The bulk modulus (K) was also more markedly improved by solidification for Sample B. The Young's modulus (E) showed corroborating trend with the small strain stiffness (K) for both samples, though in a more subdued manner compared to its small strain counterpart. 
The soil-slag mixture produced a solidified material with enhanced strength and stiffness, though with distinctive responses to compressive load, where Sample A attained lower strength improvement but greater stiffness gain, and vice versa for Sample B. This can be attributed to the stressstrain pattern obtained from the unconfined compressive strength tests. Nonetheless these differences did not affect the overall strength enhancement rate, as shown in the close scatter in Figure 11.

The apparent relationship between $\mathrm{v}_{\mathrm{p}}$ and $\varepsilon_{\mathrm{f}}$ does not necessarily represent the small strain stiffness gain in the solidified specimens, with a significant $v_{p}$ range shared within the same region of $\varepsilon_{\mathrm{f}}$. The $\mathrm{K}$ values show good correlation with the $v_{p}$ measurements, where a quadratic equation relates the parameters. The normalised $v_{p}$ however, showed less significant rise in Sample A, suggestive of less solidification effectiveness in the particular soil type.

The $\mathrm{q}_{\mathrm{u}} / \mathrm{q}_{\mathrm{u} 3}-\mathrm{v}_{\mathrm{p}} / \mathrm{v}_{\mathrm{p} 3}$ correlations are linear for both samples, though they appeared to share similar strength and stiffness gain up to the ratio of 1.5 before diverging significantly (Figure 15). The linear correlation of $\mathrm{E} / \mathrm{E}_{3} \approx$ $0.83 \mathrm{v}_{\mathrm{p}} / \mathrm{v}_{\mathrm{p} 3}$ highlights the underestimation of stiffness gain due to solidification referring to the initial rise of the compression curves. This corresponds with the comparison of the normalised stiffness modulus, i.e. $\mathrm{E}$ and $\mathrm{K}$, where $\mathrm{K}$ showed more marked increment than E. As such, it could be considered a caution against estimation of stiffness improvement based on the stress-strain curves alone.

Overall the 4 mol $\mathrm{NaOH}$-activated EAF steel slag was found to improve the strength and stiffness of the couple of dredged marine soils to various extents, with implications of further examinations required on the optimum slag addition dosage for effective solidification for a given time frame. In a nutshell, EAF steel slag can be potentially used to induce solidification in the dredged marine soil of low strength and stiffness. Nevertheless the inherent non-uniformity properties of slag make it necessary to perform trial mixes to ascertain the optimum mix ratios. The dredged soil and slag combination enables simultaneous benefits of reusing the otherwise discarded geo-wastes and industrial by-product.

\section{Acknowledgment}

Acknowledgement is due to H. Hamzah and A. N. Abdul Jalil for the laboratory work conducted. The work presented had funding support by the Ministry of Science, Technology and Innovation (MOSTI) Malaysia via the ScienceFund S025.

\section{References}

[1] J. B. Herbich, Handbook of Dredging Engineering. $2^{\text {nd }}$ edition. New York: McGraw-Hill, 2000.

[2] Y. T. Kim, J. Ahn, W. J. Han, and M. A. Gabr, "Experimental evaluation of strength chatacteristic of stabilized dredged soil," Journal of Materials in Civil Engineering, 2010, vol. 22, pp. 539544

[3] J. S. Lee, and J. C. Santamarina, "Bender elements: Performance and signal interpretation," Journal of Geotechnical and Geoenvironmental Engineering, 2005, vol. 131, pp. 1063-1070.

[4] Nippon Slag Association. 2003. www.slg.jp (accessed: 05 April 2014).

[5] C. Shi, "Steel slag: Its production, processing, characteristics and cementitious properties," Journal of Materials in Civil Engineering, 2005, vol. 16, pp. 230-236.

[6] S. Kourounis, S. Tsivilis, P. E. Tsakiridis, G. D. Papadimitriou, and Z. Tsibouki, "Properties and hydration of blended cements with steelmaking slag," Cement and Concrete Research, 2007, vol. 37, pp. 815-822.

[7] Q. Wang, and P. Yan, "Hydration properties of basic oxygen furnace steel slag," Construction and Building Materials, 2010, vol. 24, pp. 1134-1140.

[8] H. Motz, and J. Geiseler, "Product of steel slags an opportunity to save natural resources," Waste Management, 2001, vol. 21, pp. 286295

[9] H. Y. Poh, G. S. Ghataora, and N. Ghazireh, "Soil stabilization using basic oxygen steel slag fines," Journal of Materials in Civil Engineering, ASCE, March/April 2006, pp. 229-240.

[10] X. Wu, H. Zhu, X. Hou, and H. Li, "Study on steel slag and fly ash composite Portland cement," Cement and Concrete Research, 2009, vol. 29, pp. 1103-1106.

[11] A. Lindmark, A. Wilhelmsson, and A. B. Cowi, "Stabilization of contaminated sediments: a comparison of shear strength from laboratory mixing and testing and field testing," Linnaeus Eco-Tech, 2012, pp. 158-178.

[12] S. Kamali, F. Bernard, and N. E. Abriak, "Marine dredged sediments as new materials resource for road construction," Waste Management, 2008, vol. 28(5), pp. 918-928.

[13] A. A. M. Mustaffa, H. Kamarudin, A. K. Omar, M. N. Norazian, C. M. Ruzaidi, and A. R. Rafiza, "The effect of alkaline activator ratio on the compressive strength of fly ash-based geopolymer," Australian Journal of Basic and Applied Sciences, 2004, vol. 5(9), pp. 19161922.

[14] British Standards Institution (BSI). 1990. BS1377: Methods of test for soils for civil engineering purposes.

[15] J. Lai, Unconfined compression test. Department of Construction, Chaoyang University of Technology; China, 2007.

\section{About Author:}

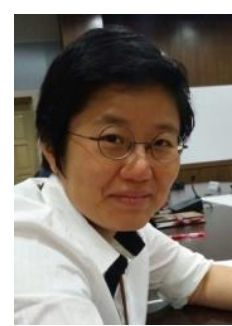

Dr. C-M Chan's expertise encompasses characterization, innovative treatment and reuse of geo-materials, especially dredged marine soils. These studies explore the material's reusability to minimize dumping and contamination or damaging risks of the marine ecosystem. 